\title{
Rancang Bangun Kendali Peralatan Rumah Tangga Berbasis Smartphone Android
}

\author{
Taufik Akbar ${ }^{*}$, Indra Gunawan ${ }^{2}$, Khairil Anwar ${ }^{3}$ \\ 1 Program Studi Teknik Komputer, Universitas Hamzanwadi \\ 2Program Studi Teknik Informatika, Universitas Hamzanwadi \\ 3Teknik Audio Video, SMK Negeri 1 Kopang \\ *aliakbar.akbar266@gmail.com
}

\begin{abstract}
Abstrak
Selama ini masyarakat pada umumnya dapat mengendalikan lampu atau peralatan elektronik lainnya hanya dengan saklar akan tetapi pengendalian tersebut dibatasi oleh jarak. Oleh karena itu, dilakukan kegiatan pembangunan sebuah prototype aplikasi sistem pengendalian peralatan elektronik yang dibangun di platform Android sebagai solusi alternatif baru untuk pengendalian jarak jauh. Aplikasi yang dibangun pada platform Android ini memiliki tampilan antarmuka (user interface) yang menarik dan mudah dipahami. Selain itu, sistem pengendalian yang dibangun memanfaatkan jaringan bluetooth untuk pengiriman instruksi pengendaliannya ke arduino. Pada prototype ini menggunakan arduino uno sebaga prosesor, android sebagai kendali, modul Bluetooth $\mathrm{HC}-06$ sebagai komunikasi arduino dengan android dan menggunakan rellay sebaga switch kontrol dengan sfesifikasi 4 chanel. Komunikasi antara smartphone android dengan mikrokontroler dapat dilakukan secara wireless menggunakan bluetooth, yang mana smartphone android dan bluetooth module pada sistem mikrokontroler dapat berkomunikasi menggunakan data serial. Fitur speech recognition yang ada pada smartphone android dapat dimanfaatkan untuk mengendalikan lampu menggunakan perintah suara. Hal ini dilakukan dengan cara menginisialisasikan spektrum perintah suara berupa string ke dalam kode karakter yang telah dikenali mikrokontroler.Pengendalian peralatan elektronik tidak akan bekerja jika smartphone android diluar jarak jangkauan pancaran wireless bluetooth dari bluetooth module karena sambungan bluetooth akan terputus secara otomatis.
\end{abstract}

Kata Kunci :Android, Arduino Uno, Bluetooth HC-06.

\begin{abstract}
So far, the community in general can control lights or other electronic equipment with just a switch, but the control is limited by distance. Therefore, the construction of an electronic equipment control system application prototype was built on the Android platform as a new alternative solution for remote control. The application built on the Android platform has an attractive and easy to understand user interface. In addition, the control system built utilizes a Bluetooth network for sending control instructions to Arduino. In this prototype using Arduino Uno as a processor, Android as a control, Bluetooth $\mathrm{HC}-06$ module as Arduino communication with Android and using relay as a control switch with 4 channel specifications. Communication between an android smartphone and a microcontroller can be done wirelessly using Bluetooth, which the Android smartphone and Bluetooth module on the microcontroller system can communicate using serial data. The speech recognition feature on an Android smartphone can be used to control the lights using voice commands. This is done by initializing the spectrum of voice commands in the form of strings into character codes that have been identified by the microcontroller. Control of electronic equipment will not work if the Android smartphone is out of range of the Bluetooth wireless transmission range of the Bluetooth module because the Bluetooth connection will be disconnected automatically.
\end{abstract}

Keywords: Android,ArduinoUno,BluetoothHC-06.

\section{Pendahuluan}

Perkembangan teknologi saat ini sangat pesat.

Dibuktikan saat ini Indonesia sudah masuk pada era industri 4.0. TeKnologi ini kita akan manfaatkan untuk keperluan sehari-hari. Selama ini masyarakat pada umumnya dapat 
mengendalikan lampu atau peralatan elektronik lainnya hanya dengan saklar akan tetapi pengendalian tersebut dibatasi oleh jarak. Jangkauan yang lumayan jauh terlebih lagi apabila rumahnya adalah rumah yang bertingkat sehingga melelahkan jika harus menuju saklar lampu menhidupkan atau mematikan lampu atau peralatan elektronik lainnya .

Apabila seluruh lampu atau peralatan elektronik lainnya dalam suatu rumah dikendalikan tanpa harus menyalakan saklar di dalam rumah maka peran mikrokontroler, smartphone android, serta fasilitas bluetooth sangat penting untuk memberi kenyamana dan kemudahan khususnya, untuk orang yang memiliki aktifitas yang padat di luar rumah dan para penyandang cacat fisik atau orang yang sudah tua. Android merupakan sebuah sistem operasi pada ponsel berbasis Linux yang mencakup sistem operasi, fasilitas opensource atau sistem operasi yang dapat dikembangkan dengan bebas bagi penggunanya, membuat banyak orang untuk mengembangkannya dengan inovasi - inovasi yang semakin berkembang terhadap sistem operasinya maupun pada pembangunan aplikasi mobile nya tersebut. Tak heran saat ini banyak pengembang yang membangun aplikasi mobile pada platform Android. Pemanfaatan smartphone android sebagai alat komunikasi dan telepon cerdas telah banyak mengalami perkembangan saat ini, seperti sebagai alat pengendalian lampu penerangan rumah yang dipadukan dengan komponen mikrokontroler dan memanfaatkan fasilitas bluetooth yang ada pada smartphone android. Oleh karena itu, dilakukan kegiatan pembangunan sebuah prototype aplikasi sistem pengendalian peralatan elektronik yang dibangun di platform Android sebagai solusi alternatif baru untuk pengendalian jarak jauh. Aplikasi yang dibangun pada platform Android ini memiliki tampilan antarmuka (user interface) yang menarik dan mudah dipahami. Selain itu, sistem pengendalian yang dibangun memanfaatkan jaringan bluetooth untuk pengiriman instruksi pengendaliannya ke arduino.

\section{Tinjauan Pustaka}

\subsection{Penelitian Terkait}

- Penelitian dengan tema Smart Home berbasis bluetooth pernah ditulis Kurnia Agung Pamungkas dkk, pada Jurnal IImiah NERO Vol. 2, No.3 2016 , dengan judul "Aplikasi Android dan Mikrokontroller Arduino pada Kontrol Smarthome dengan Komunikasi Bluetooth", Pada artikel ini menggunakan arduino Uno ,rellay ,Motor DC, Modul Bluetooth.

- Penulisan terkait juga pernah ditulis I Wayan Boby Astagina Naghi dkk dalam artikel Jurnal Pengembangan Teknologi Informasi dan IImu Komputer e-ISSN: 2548-964X Vol. 1, No. 9, Juni 2017 dengan judul " Implementasi Sistem Pervasive Pada Smart Home Berbasis Bluetooth Versi 4.0 Menggunakan Modul BLE HM-10 dan Sensor ". Pada artiel ini 
menggunakan Arduino Uno dan Arduino Nano.

- Resi Ikhwan Nugraha dkk juga menulis artikel pada Jurnal JUMANTAKA Vol 01 No 01 (2018) PISSN: 2613-9138 - EISSN : 26139146 dengan judul "Simulasi Smart Home Berbasis Arduino" ,pada penelitian ini menggunaan modul bluetooh $\mathrm{HC}-06$.

- Angger Dimas Bayu Sadewo dkk juga menulis artikel pada Jurnal Pengembangan Teknologi Informasi dan IImu Komputer eISSN: 2548-964X

Vol. 1, No. 5, Mei 2017, dengan judul Perancangan Pengendali Rumah menggunakan Smartphone Android dengan Konektivitas Bluetooth.

- Muhamad Muslihudin dkk menulis arikel pada jurnal Jurnal Keteknikan dan Sains (JUTEKS) - LPPM UNHAS Vol. 1, No.1, Juni 2018 dengan judul "Implementasi Aplikasi Rumah Pintar Berbasis Android dengan Arduino Microcontroller".

\subsection{Landasan Teori}

\section{Arduino Uno}

Arduino adalah platform pembuatan prototipe elektronik yang bersifat open-source hardware yang berdasarkan pada perangkat keras dan perangkat lunak yang fleksibel dan mudah digunakan. Arduino ditujukan bagi para seniman, desainer, dan siapapun yang tertarik dalam menciptakan objek atau lingkungan yang interaktif. Arduino pada awalnya dikembangkan di Ivrea, Italia. Nama Arduino adalah sebuah nama maskulin yang berarti teman yang kuat. Platform arduino terdiri dari arduino board, shield, bahasa pemrograman arduino, dan arduino development environment. Arduino board biasanya memiliki sebuah chip dasar mikrokontroler Atmel AVR ATmega8

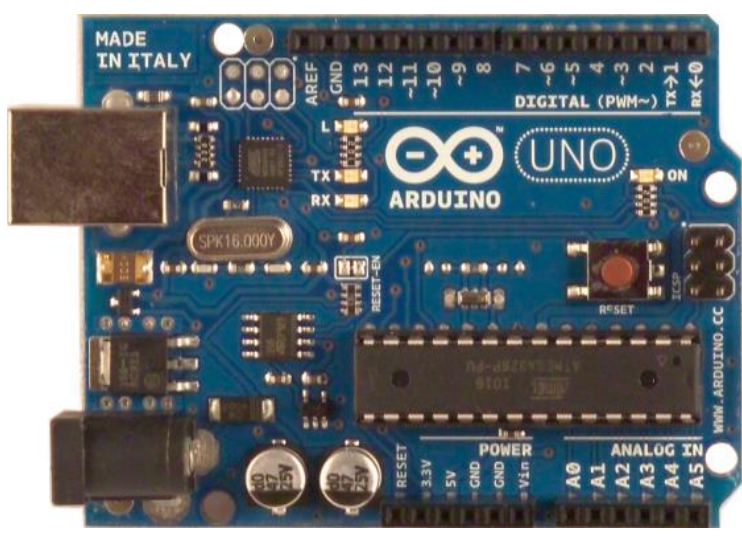

Gambar 1. Arduino Uno

2. App Inventor

M. S,.Pd 2017 menyatakan bahwa App inventor adalah integrated devlovment (IDE) yang di tujukan bagi semua kalangan untuk mengembangkan aplikasi - aplikasi android tanpa harus berpengalaman dalam dunia pemerograman sebelumnya. App Inventor memungkinkan pengguna baru untuk memprogram komputer untuk menciptakan aplikasi perangkat lunak bagi sistem operasi Android. App Inventor menggunakan antarmuka grafis, serupa dengan antarmuka pengguna pada Scratch dan StarLogo TNG, yang memungkinkan pengguna untuk men-drag-anddrop objek visual untuk menciptakan aplikasi yang bisa dijalankan pada perangkat Android.

3. Bluetooth Module HC-06 
Bluetooth adalah spesifikasi industri untuk jaringan kawasan pribadi (personal area network atau PAN) tanpa kabel. Bluetooth menghubungkan dan dapat dipakai untuk melakukan tukar-menukar informasi di antara peralatan-peraltan. Spesifikasi dari peralatan Bluetooth ini di kembangkan dan didistribusikan oleh kelompok Bluetooth Special Interest Group.

Bluetooth beroperasi dalam pita frekuensi 2,4

Ghz dengan menggunakan sebuah frequency hopping traceiver yang mampu menyediakan layanan komunikasi data dan suara secara real time antar host-host Bluetooth dengan jarak terbatas. Kelemahan teknologi ini adalah jangkauannya yang pendekdan kemampuan transfer data yang rendah.

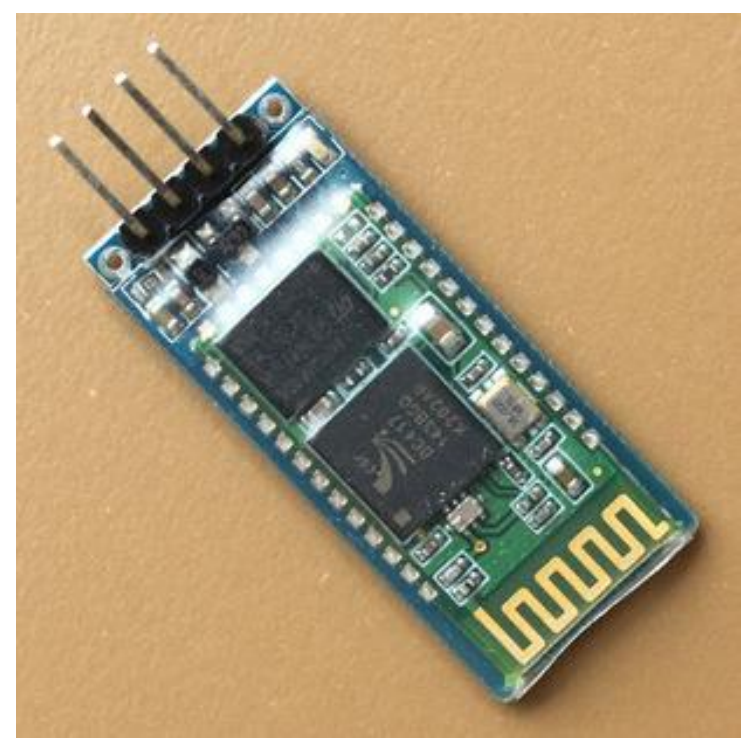

Gambar 2 Bluetooth Module

HC-06

\section{Rellay}

Relay adalah Saklar (Switch) yang dioperasikan secara listrik dan merupakan komponen
Electromechanical (Elektromekanikal) yang terdiri dari 2 bagian utama yakni Elektromagnet (Coil) dan Mekanikal (seperangkat Kontak Saklar/Switch). Relay menggunakan Prinsip Elektromagnetik untuk menggerakkan Kontak Saklar sehingga dengan arus listrik yang kecil (low power) dapat menghantarkan listrik yang bertegangan lebih tinggi. Sebagai contoh, dengan Relay yang menggunakan Elektromagnet $5 \mathrm{~V}$ dan $50 \mathrm{~mA}$ mampu menggerakan Armature Relay (yang berfungsi sebagai saklarnya) untuk menghantarkan listrik $220 \mathrm{~V} 2 \mathrm{~A}$.

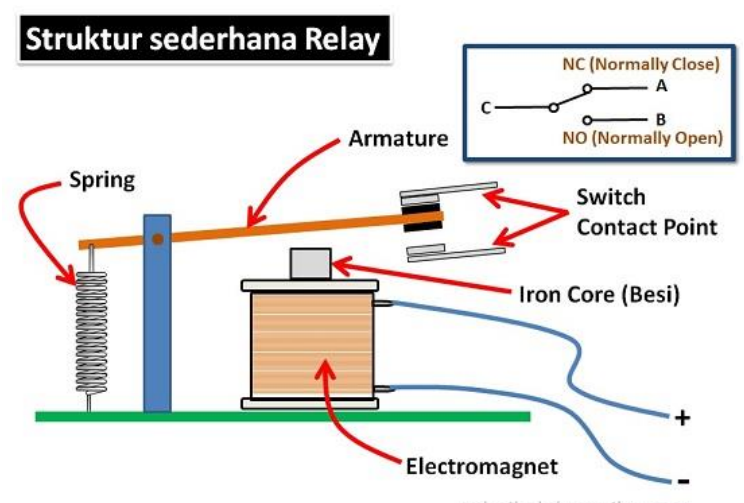

Gambar 3. Struktur Sederhana Rellay

\section{Metode Penelitian}

Dalam sistem ini, user melakukan input dari aplikasi kendali yang ada pada perangkat smartphone android. Tersedia hanya satu macam pilihan input yaitu standar input (button on/off lampu) Data paralel yang dihasilkan oleh mikrokontroler arduino diteruskan ke relay melalui indikator led yang berfungsi untuk memastikan apabila lampu hidup, led juga akan hidup, begitu juga sebaliknya. Kemudian relay akan meneruskan data yang digunakan untuk 
menghidupkan atau mematikan beban rumah tangga. Berikut adalah activity diagram pada sistem baru:

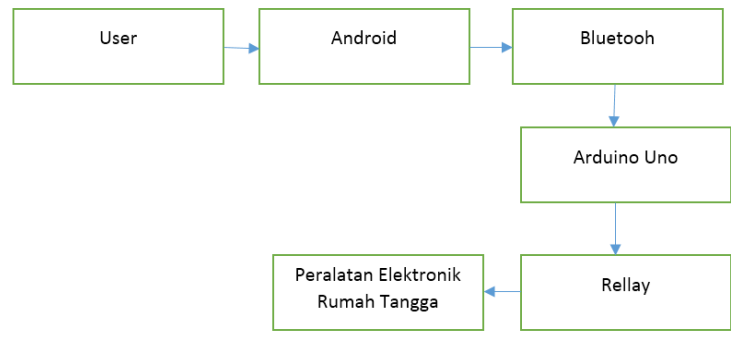

Gambar 4. Activity diagram aliran kerja sistem baru

\section{Hasil dan Pembahasan}

a. Rancangan Perangkat Keras (Hardware)

Perancangan perangkat keras merupakan rancangan atau rangkaian dari alat yang digunakan untuk membangun prototipe pengendalian peralatan elektronik berbasis mikrokontroler arduino menggunakan smartphone android

\section{b. Perancangan Rellay dengan Arduino}

Rellay disini menggunakan 4 chanel, artinya hanya bisa mengontrol 4 buah beban perangkat rumah tangga

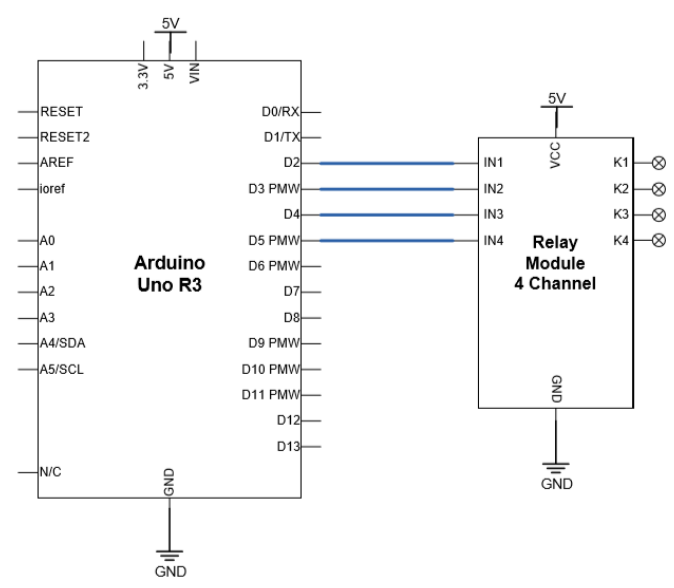

Gambar 5. Skema Rellay

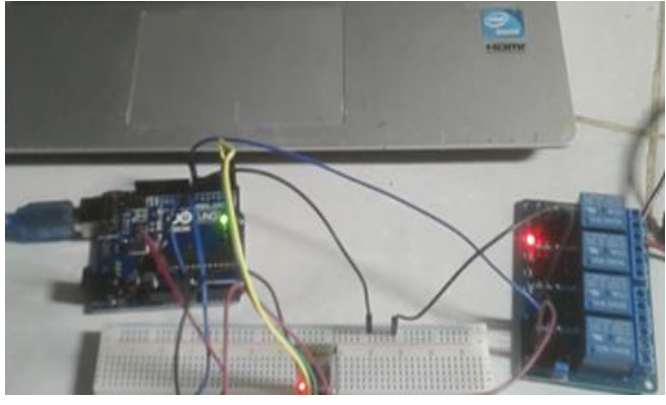

Gambar 6. Hasil Instalasi Rellay dengan Arduino

c. Perancangan bluetooth module HC-06 dengan Arduino.

Rangkaian bluetooth module HC-06 dengan arduino digunakan untuk menghubungkan antara smartphone android dengan bluetooth module yang terhubung dengan board arduino agar perintah-perintah yang dikirim dari smartphone android dapat diterima dan dieksekusi oleh mikrokontroler arduino melalui komunikasi jaringan Bluetooth

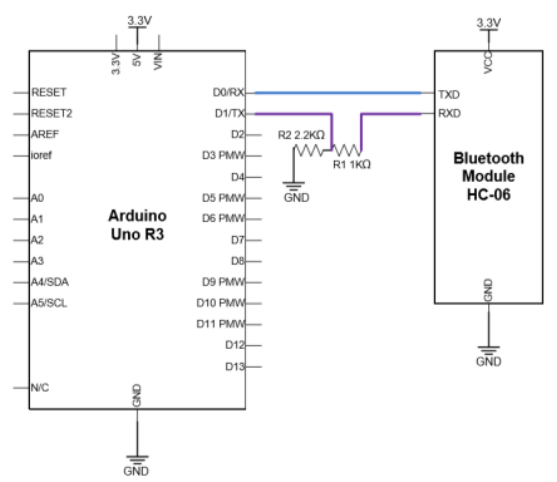

Gambar 7. Skema Modul Bluetooth hc-06

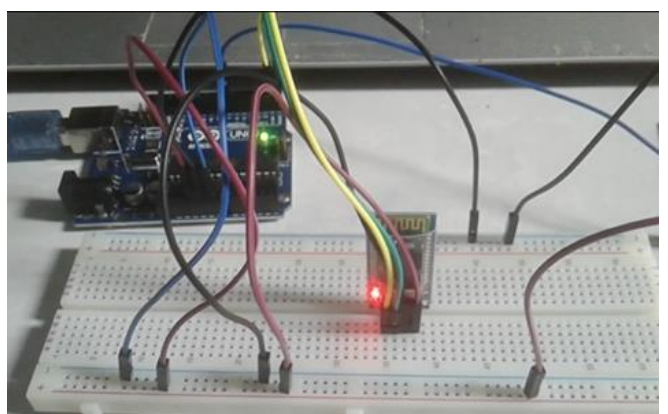


Gambar 8. Hasil instalasi Bluetooth dengan Arduino

\section{d. Perancangan Perangkat Lunak}

Pada sistem ini, perancangan perangkat lunak dapat dibedakan menjadi dua bagian yaitu perancangan perangkat lunak pada modul pengendali utama (Papan Mikrokontroler Arduino Uno) dan perancangan perangkat lunak pengendali pada smartphone android sebagai antarmuka untuk pengguna.

\section{e. Perancangan Perangkat Lunak Pengendali utama (arduino)}

Pada arduino Sebelum ketahap berikutnya, maka terlebih dahulu dibuatlah flowchart proses upload kode program atau sketch ke papan arduino, dengan flowchart sebagai berikut:

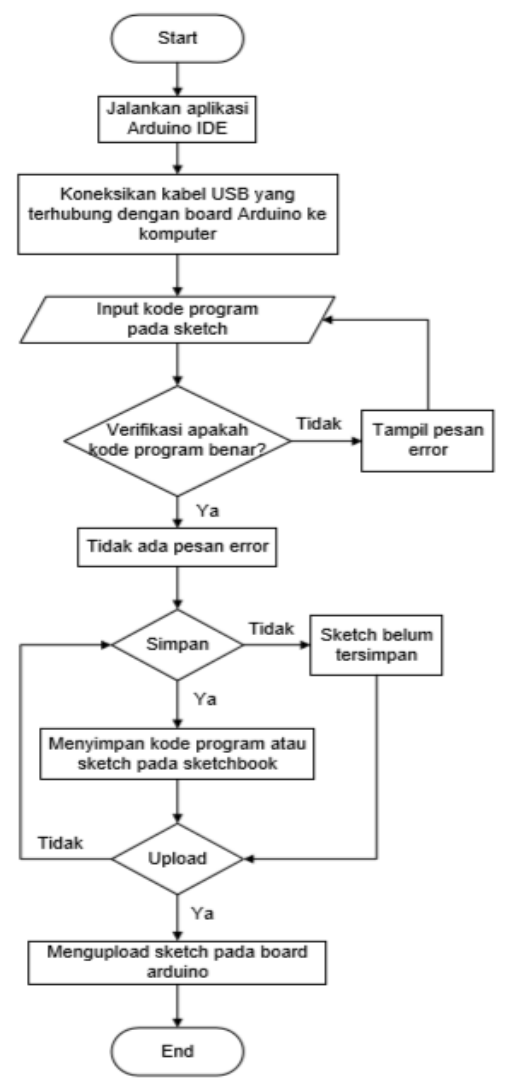

Gambar 9. Flowchart Program Arduino
Langkah awal yang harus dilakukan adalah dengan menentukan logika yang akan diterapkan pada lampu yang akan dikendalikan, kemudian membuat algoritmanya yang kemudian di implementasikan menggunakan Arduino IDE.

Tabel 1. Logika Beban Rumah Tangga.

\begin{tabular}{|c|c|c|c|c|}
\hline Parintah & Lampu 1 & Lampu 2 & Lampu 3 & Lampu 4 \\
\hline $\mathbf{1}$ & ON/OFF & - & - & - \\
\hline $\mathbf{2}$ & - & ON/OFF & - & - \\
\hline $\mathbf{3}$ & - & - & ON/OFF & - \\
\hline $\mathbf{4}$ & - & - & - & ON/OFF \\
\hline $\mathbf{5}$ & ON/OFF & ON/OFF & ON/OFF & ON/OFF \\
\hline $\mathbf{s}$ & Status : & Status : & Status : & Status : \\
& ON/OFF & ON/OFF & ON/OFF & ON/OFF \\
\hline
\end{tabular}

Dari logika tersebut, maka dibuatlah flowchart input perintah dari perangkat lunak yang akan ditanam di dalam mikrokontroler Arduino Uno, yaitu sebagai berikut:

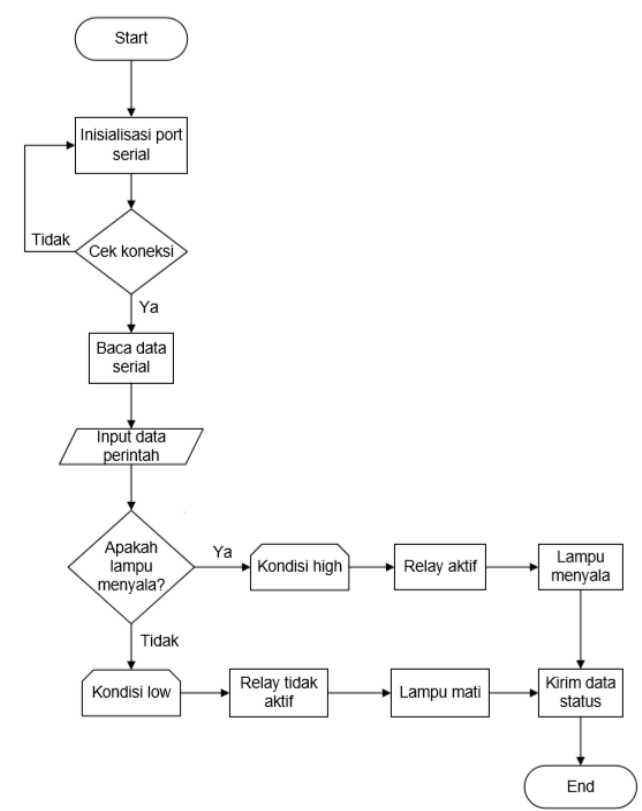

Gambar 10. Flowchart input perintah dari perangkat lunak.

f. Perancangan Perangkat Lunak Pengandali Smartphone.

Pada smartphone android Perancangan perangkat lunak pada smartphone android dalam 
sistem ini merupakan bentuk tampilan dari program yang tampil pada layar smartphone android dengan bertujuan untuk memberikan gambaran tentang aplikasi yang akan dibangun, sehingga akan mempermudahkan pengimplementasian aplikasi sesuai denga ukuran layar dan mempermudahkan dalam pembuatan aplikasi. Berikut ini adalah rancangan layar pada aplikasi android yang akan digunakan untuk mengendalikan peralatan elektronik rumah

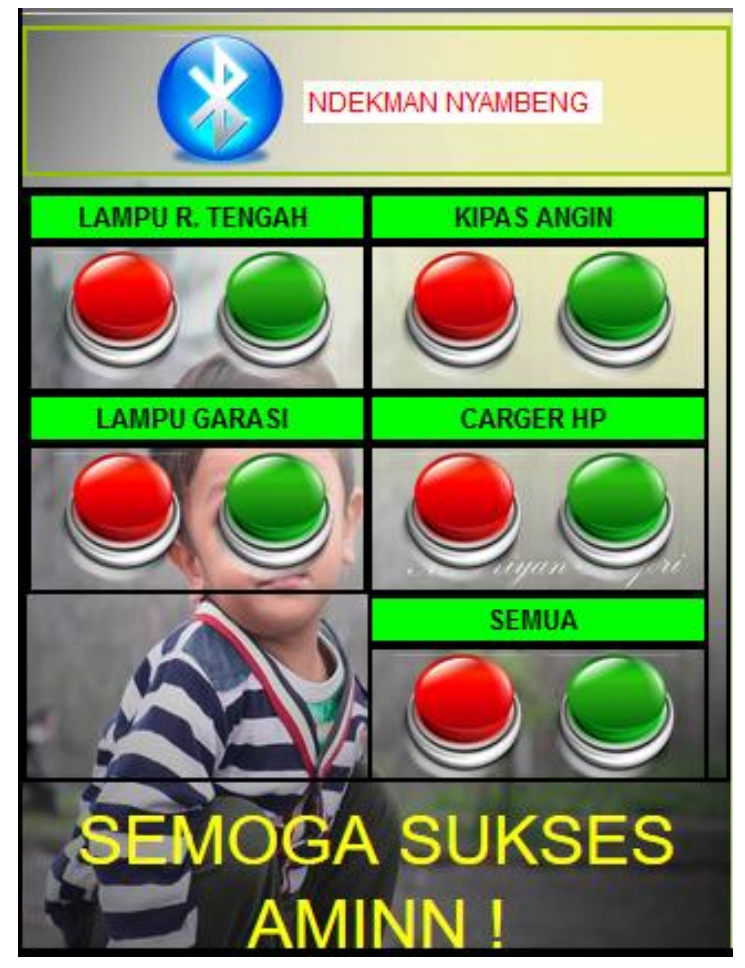

Gambar 11. Tampilan di Smartphone.

\section{Kesimpulan}

Berdasar hasil analisis, perancangan dan implementasi yang telah dilakukan, serta berdasarkan rumusan masalah yang ada, maka dapat diambil beberapa kesimpulan diantaranya sebagai berikut:

a) Komunikasi antara smartphone android dengan mikrokontroler dapat dilakukan secara wireless menggunakan bluetooth, yang mana smartphone android dan bluetooth module pada sistem mikrokontroler dapat berkomunikasi menggunakan data serial.

b) Fitur speech recognition yang ada pada smartphone android dapat dimanfaatkan untuk mengendalikan lampu menggunakan perintah suara. Hal ini dilakukan dengan cara menginisialisasikan spektrum perintah suara berupa string ke dalam kode karakter yang telah dikenali mikrokontroler.

c) Pengendalian peralatan elektronik tidak akan bekerja jika smartphone android diluar jarak jangkauan pancaran wireless bluetooth dari bluetooth module karena sambungan bluetooth akan terputus secara otomatis.

\section{Daftar Pustaka}

[1] Angger Dimas Bayu Sadewo dkk, Perancangan Pengendali Rumah menggunakan Smartphone Android dengan Konektivitas Bluetooth, Jurnal Pengembangan Teknologi Informasi dan IImu Komputer e-ISSN: 2548-964X Vol. 1, No. 5, Mei 2017.

[2] I Wayan Boby Astagina Naghi dkk , Implementasi Sistem Pervasive Pada Smart Home Berbasis Bluetooth Versi 4.0 Menggunakan Modul BLE HM-10 dan Sensor , Jurnal Pengembangan Teknologi Informasi dan IImu Komputer e-ISSN: 2548-964X Vol. 1, No. 9, Juni 2017. 
[3] Kurnia Agung Pamungkas dkk, "Aplikasi Android dan Mikrokontroller Arduino pada Kontrol Smarthome dengan Komunikasi Bluetooth" Jurnal IImiah NERO Vol. 2, No.3 2016.

[4] Muhamad Muslihudin dkk, Implementasi Aplikasi Rumah Pintar Berbasis Android dengan Arduino Microcontroller, Jurnal Keteknikan dan Sains (JUTEKS) - LPPM UNHAS Vol. 1, No.1, Juni 2018.

[5] Resi lkhwan Nugraha dkk, Simulasi Smart Home Berbasis Arduino, JUMANTAKA Vol 01 No 01 (2018) PISSN: 2613-9138 EISSN : 2613-9146 